\title{
Analisis Defect Proses Produksi Songkok Berbasis Metode FMEA dan FTA di Home - Industri Songkok GSA Lamongan
}

\author{
Ayu Lestari ${ }^{1^{*}}$, Nina Aini Mahbubah ${ }^{2 *}$ \\ ${ }^{1,2}$ Program Studi Teknik Industri, Fakultas Teknik, Universitas Muhammadiyah Gresik \\ Jl. Sumatera 101 GKB Gresik, Indonesia 61121 \\ *Koresponden email: n.mahbubah@umg.ac.id, ayulestari_170601@umg.ac.id
}

Diterima : 28 Juli 2021

Disetujui : 14 Agustus 2021

\begin{abstract}
Small and medium-sized enterprises are recognized as a national safety net during the crisis era in this country. Gangsar is a small business and is recognized as a songkok household industry in Lamongan City. Maintaining sustainable quality is considered both a challenge and a weakness to sustain its operations . The research purpose is to identify defects and analyze them to improve the quality of the product. Failure mode and effect analysis and fault tree analysis were used as research methods. This research began with mapping the flow production process to identify the defective product. Once the defective product was identified, the next step was to determine the risk priority number. The mapping failure tree was the next step to detecting fault mode. The results revealed three identified defects, namely the trim with the risk priority number144, the disordered sewing process with RPN 126 and the non-precision cutting fabric with RPN 86. These defects were analyzed using FTA and factors such as human error, bad materials, and broken sewing machines must be eliminated. Improved work facilities and regular training and supervision of the work are considered a best case scenario to maintain product quality.
\end{abstract}

Keywords: Songkok, Defect, FMEA, FTA, RPN

\begin{abstract}
Abstrak
Usaha Menengah Menengah (UKM) diakui sebagai jaring pengaman nasional di masa krisis di negeri ini. Gangsar adalah usaha menengah dan diakui sebagai industri rumah tangga songkok yang berada di Kota Lamongan. Mempertahankan kualitas yang berkelanjutan merupakan tantangan sekaligus kelemahan untuk mempertahankan kelangsungan usahanya. Tujuan penelitian adalah untuk mengidentifikasi defect serta merancang skenario yang lebih baik untuk meningkatkan kualitas produk. Metode Kegagalan dan Analisis Efek dan Analisis Pohon Kesalahan telah digunakan sebagai metode penelitian. Penelitian ini diawali dengan pemetaan alur proses produksi untuk mengidentifikasi produk defect. Setelah produk defect dikenali, tahap selanjutnya adalah menghitung nomor prioritas risiko. Pemetaan pohon kesalahan adalah tahap selanjutnya untuk mendeteksi mode kegagalan. Hasil penelitian menunjukkan tiga defect yang teridentifikasi yaitu trimming dengan Risk Priority Number 144, proses penjahitan yang tidak teratur dengan RPN 126 dan pemotongan kain yang tidak presisi dengan RPN 86. Defect ini telah dianalisis menggunakan FTA dan ditemukan faktor-faktor seperti human error, material yang tidak baik, dan mesin jahit yang rusak perlu dihilangkan. Peningkatan fasilitas kerja dan pelatihan berkala serta pengawasan kerja dianggap sebagai skenario yang lebih baik untuk mempertahankan kualitas produk.
\end{abstract}

Kata Kunci: Songkok, Defect, FMEA, FTA, DMAIC, RPN

\section{Pendahuluan}

Perkembangan home industry saat ini tidak lepas dari pertumbuhan teknologi dan kemampuan inovasi dalam bidang proses serta pengendalian dan penjaminan mutu yang dikehendaki sejalan dengan pengembangan IPTEK serta dalam rangka menghadapi era industri ekonomi kreatif. Karena tuntutan kondisi industri saat ini menimbulkan efek samping yaitu tingginya persaingan antar sesama industri [1]. Setiap home industry harus benar-benar cermat dan tidak hanya fokus pada kualitas produk, akan tetapi juga meningkatkan kualitas pada aspek lainnya yang termasuk dalam sistem usahanya. Seperti halnya, kualitas bahan mentah dari pemasok, kualitas tenaga kerja, kualitas mesin dan teknologi yang digunakan, sistem pemasaran yang efektif, serta sistem distribusi yang tepat waktu [2]. Menurut ref. [3] dengan seiring berkembangnya dunia industri maka setiap usaha akan berfokus pada kepuasan pelanggan guna memenangkan persaingan antar industri.

Gangsar (GSA) merupakan salah satu home industry yang memproduksi produk songkok. Industri ini milik H. Gangsar yang berlokasi di Desa Pengangsalan Kecamatan Kalitengah Kabupaten Lamongan. 
Berdasarkan data dinas kependudukan tahun 2020 hampir semua penduduk di desa ini yang berjumlah kurang lebih 1872 jiwa merupakan pengrajin songkok sejak tahun 1983. Sampai saat ini usaha songkok ini masih terus berkembang ditandai dengan setiap harinya para pekerja bisa menyelesaikan order 200 sampai 400 pcs songkok. Usaha ini banyak memproduksi songkok sesuai permintaan pasar dan wilayah pemasaran adalah area Gresik, Lamongan, dan Surabaya.

Menurut ref. [4], produk songkok didefinisikan sebagai suatu alat yang berfungsi untuk menutup kepala bagi kaum pria yang biasanya digunakan untuk ibadah sholat ataupun pengajian bagi umat muslim. Produk songkok terbuat dari bahan kain beludru, kain kardilak, kain keras dan bahan pendukung lainnya yang dipotong setengah lingkaran kemudian dilakukan penjahitan untuk menyatukan body dari songkok itu sendiri. Sedangkan dinegara lain seperti Amerika dan Eropa, penduduknya memberi sebutan songkok dengan nama kufi, taqiyat, topi fez.

Perbaikan kualitas di industri skala besar ataupun skala UKM telah diteliti dan dikembangkan. Peneliti [5] menganalisis perbaikan kualitas produk menggunakan metode FTA (Fault Tree Analysis) dan FMEA (Failure Mode and Effect Analysis) di PT. IFMFI Surabaya. Menurut ref. [6] defect adalah produk yang tidak memenuhi standar kualitas yang ditetapkan dan tidak dapat dilanjutkan ke tahapan proses berikutnya. Produk ini dengan biaya rekondisi untuk proses perbaikan, secara ekonomis produk tersebut dapat disempurnakan dengan menjadi produk jadi yang lebih baik. Hasil penelitian sebelumnya menunjukkan ditemukan 5 jenis defect, yaitu defect berlubang dengan nilai probabilitas $6,5 \%$, defect gosong dengan probabilitas 5,9\%, dan defect bantat dengan probabilitas 6,9\%. Peneliti [7] menganalisis penyebab kedefectan produk sepatu $t$ dengan menggunakan metode FTA dan FMEA di PT. Panarub Industri. Hasil pembahasan dari penelitian ini menunjukkan proses sewing dengan nilai 576 dan assembling skor 512. Adapun yang mendapatkan nilai RPN tertinggi mempunyai tingkat defect mayor.

Berdasarkan hasil observasi di lapangan diketahui bahwa UKM GSA mengalami permasalahan mengenai kualitas, yaitu temuan adanya jumlah defect produk dalam jumlah tinggi yang berakibat terhadap rework produk tersebut sehingga biaya produksi ikut membengkak dan pemilik pun mengalami kerugian. Persentase defect yang terjadi pada produk songkok GSA pada periode April sampai Juni 2020 mencapai $3,08 \%$ sementara target defect product yang diperbolehkan oleh pemilik yaitu hanya $2 \%$. Karena terdapat kelebihan jumlah produk defect yang teridentifikasi maka akan mengakibatkan timbulnya waste pada usaha songkok tersebut. Diketahui jika songkok yang lolos hingga tahap packaging, maka songkok tersebut akan diturunkan grade sesuai dengan kondisi songkok yang defect.

Hal ini perlu dilakukan penelitian untuk mengidentifikasi masalah penentuan prioritas jenis kegagalan dalam proses produksi songkok. Adapun metode yang digunakan dalam mendeteksi potensi kegagalan dalam suatu proses produksi adalah Failure Mode and Effect Analysis (FMEA) dan Fault Tree Analysis (FTA). Menurut ref. [8], produk defect yaitu suatu produk hasil produksi yang tidak sesuai standar, kualitasnya rendah, tidak diterima dengan baik oleh konsumen, dan ada kemungkinan tidak dapat diperbaiki menjadi produk yang baik. Kualitas didefinisikan sebagai suatu sifat dari produk ataupun service yang memiliki pengaruh untuk dapat memberikan kepuasan terhadap kebutuhan yang ada [9]. Produk didefinisikan sebagai suatu barang yang dapat ditawarkan/ diperjualbelikan ke orang lain sehingga dapat memuaskan orang yang membeli [1].

Menurut ref. [10], pengendalian kualitas merupakan alat verifikasi untuk menentukan tingkatan kualitas produk atau service sesuai harapan yang dilakukan dengan cara perencanaan, penggunaan metode yang sesuai, pengawasan yang dilakukan secara rutin serta tindakan perbaikan bila ditemukan suatu kondisi yang tidak sesuai agar pengendalian kualitas dapat dilakukan dengan benar dan sesuai standar yang ada. Menurut ref. [11], metode FTA didefinisikan sebagai salah satu teknik yang digunakan untuk identifikasi risiko yang memiliki peran terhadap terjadinya suatu kegagalan produk. Metode ini merupakan salah satu analytical tool yang dapat mendefinisikan secara rinci suatu kesalahan yang menyebabkan kesalahan ataupun kegagalan dalam sebuah sistem produksi dengan bantuan grafik. Menurut ref. [6] Failure Mode and Effect Analysis merupakan suatu metode dengan pendekatan sistematik yang menggunakan bantuan penyelesaian tabel sebagai proses pemikiran engineers yang bertujuan untuk mengidentifikasi mode kegagalan dari potensial dan efek dari defect product [1]. Metode ini dapat melakukan suatu skala prioritas perbaikan dari tiap mode kegagalan yang terjadi sehingga memudahkan langkah perbaikan [12]. Menurut ref. [13], secara umum FMEA merupakan suatu metode yang dapat mengidentifikasi tiga poin, adapun sebagai berikut:

1. Peluang terjadinya mode kegagalan yang potensial dari suatu proses atau sistem (occurance)

2. Efek atau dampak dari terjadinya kegagalan tersebut (severity)

3. Kontrol yang dilakukan pada suatu kegagalan yang terjadi (Detection) 
Penelitian ini bertujuan untuk mengidentifikasi dan menganalisis penyebab defect menggunakan pendekatan Failure Mode and Effect Analysis (FMEA) dan Fault Tree Analysis (FTA). Kedua pendekatan tersebut memiliki kemampuan menganalisis penyebab dan mendeteksi akar permasalahan yang menyebabkan terjadinya defect selama proses produksi. Terlebih pada industri skala menengah seperti UKM GSA yang pengerjaannya banyak menggunakan tenaga manusia (manual) sehingga rentan terjadinya defect. Disamping itu, produknya harus dapat bersaing dengan para kompetitor yang banyak menggunakan tenaga mesin dengan harga dan kualitas yang kompetitif.

\section{Metode Penelitian}

Penelitian ini menggunakan pendekatan deskriptif kuantitatif berbasis studi kasus di usaha produksi songkok. Responden penelitian ini adalah pemilik usaha songkok dan karyawan bagian produksi di home industry GSA. Walk through survey dan wawancara dengan pemilik dan pegawai UKM GSA merupakan aktivitas pengumpulan data. Data historis berupa product reject dan jumlah produksi merupakan data pendukung yang digunakan di penelitian ini. Tahapan penelitian diawali dengan pengumpulan data defect pada sepanjang alur proses produksi berdasarkan hasil pemetaan tahapan proses produksi dan diakhiri dengan rekomendasi skenario terbaik guna meminimalisasi defect di UKM tersebut.

Tahap kedua yaitu penyebaran kuesioner FMEA pada responden penelitian yaitu owner dan pekerja UKM GSA. Setelah didapatkan hasil kuesioner, tahap selanjutnya yaitu perhitungan nilai RPN dengan cara perkalian antara severity, occurence, dan detection. Delapan langkah FMEA sebagai berikut [14]:

1. Mengidentifikasi jalannya proses produksi

2. Mengidentifikasi potensi failure mode dari suatu proses produksi

3. Mengidentifikasi potensi dampak kegagalan produksi

4. Mengidentifikasi penyebab dari kegagalan di proses produksi

5. Mengidentifikasi mode deteksi pada proses produksi

6. Memberikan penilaian rating untuk nilai severity, occurance and detection

7. Perhitungan nilai RPN dengan perkalian nilai severity, occurance and detection

8. Memberikan usulan perbaikan untuk kegagalan yang terjadi

Tabel 1. Nilai Severity

\begin{tabular}{llc}
\hline \multicolumn{1}{c}{ Effect } & \multicolumn{1}{c}{ Severity Effect for FMEA } & Rangking \\
\hline Tidak ada & Bentuk kegagalan tidak ada efek samping & 1 \\
Sangat minor & Tidak berakibat langsung & 2 \\
Minor & Efek terbatas & 3 \\
Sangat rendah & Perlu sedikit rework & 4 \\
Rendah & Memerlukan rework cukup banyak & 5 \\
Sedang & Produk rusak (reject) & 6 \\
Tinggi & Mengakibatkan gangguan peralatan & 7 \\
Sangat tinggi & Mengakibatkan gangguan mesin & 8 \\
Berbahaya peringatan & Gangguan mesin sehingga mesin berhenti & 9 \\
Berbahaya tanpa adanya peringatan & Mengakibatkan gangguan mesin serta & 10 \\
& mengancam keselamatan pekerja & \\
\hline
\end{tabular}

Sumber: [15]

Berdasarkan Tabel 1 dapat diketahui mengenai kriteria severity atau terkait penilaian dampak persoalan.

Tabel 2. Nilai Occurance

\begin{tabular}{ccc}
\hline Probability of Failure & Filure Rates & Rating \\
\hline Sangat Tinggi & 1 in 2 & 10 \\
Tinggi & 1 in 3 & 9 \\
& 1 in 8 & 8 \\
Sedang & 1 in 20 & 7 \\
& 1 in 80 & 6 \\
Rendah & 1 in 400 & 5 \\
Sangat Rendah & 1 in 2000 & 4 \\
Remote & 1 in 15000 & 3 \\
& 1 in 150000 & 2 \\
\hline
\end{tabular}

Sumber: [15] 
Berdasarkan Tabel 2 dapat diketahui mengenai kriteria penilaian peluang penyebab terjadinya suatu kegagalan pada suatu usaha. Penilaian ini juga didasarkan atas hasil kuesioner yang disebar kepada responden. Nilai Detection dapat dilihat pada Tabel 3.

Tabel 3. Nilai Detection

\begin{tabular}{ccc}
\hline Detection & Criteria of Detection By Process & Rangking \\
\hline Hampir tidak mungkin & Tidak ada alat pengontrol & 10 \\
Sangat jarang & Alat pengontrol yang sulit dipahami & 9 \\
Jarang & $\begin{array}{c}\text { Alat pengontrol sulit mendeteksi bentuk dan } \\
\text { penyebab kegagalan sangat rendah }\end{array}$ & 8 \\
Sangat rendah & Kemampuan control kegagalan & 7 \\
& sangat rendah & \\
Rendah & Kemampuan control kegagalan rendah & 6 \\
Sedang & Kemampuan control kegagalan sedang & 5 \\
Agak tinggi & Kemampuan control kegagalan & 4 \\
Tinggi & sangat tinggi & \\
Sangat tinggi & Kemampuan control kegagalan tinggi & 3 \\
Hampir pasti & Kemampuan control kegagalan & 2 \\
& sangat tinggi & 1 \\
\hline
\end{tabular}

Sumber: [15]

Berdasarkan Tabel 3 dapat diketahui mengenai perkiraan tentang bagaimana efektivitas dari alat kontrol dari adanya bentuk kegagalan yang terjadi. Penilaian ini juga didasarkan atas hasil kuesioner yang disebar kepada responden. Tahap selanjutnya adalah pemetaan FTA sesuai ref. [1], terdapat 5 steps dalam melakukan suatu analisis dengan menggunakan metode FTA (Fault Tree Analysis), yaitu:

1. Mendefinisikan suatu permasalahan dan kondisi

2. Membuat gambaran model grafis dari Fault Tree

3. Mencari minimal cut set dari suatu analisa Fault tree

4. Melakukan suatu analisa kualitatif dari Fault Tree

5. Melakukan suatu analisa kuantitatif dari Fault Tree.

\section{Hasil dan Pembahasan}

Berdasarkan hasil observasi dan wawancara di UKM GSA. Diagram alur merupakan penggambaran awal dari proses produksi pembuatan songkok. Pembahasan kedua yaitu rekapitulasi jumlah defect pada sepanjang alur proses produksi. Data jenis defect selanjutnya digunakan sebagai analisis untuk menentukan nilai RPN berdasarkan occurrence, severity dan detection. Selanjutnya penggambaran tiga FTA berdasarkan tiga jenis defect tersebut guna mengetahui penyebab defect secara komprehensif. Diagram alur pembuatan songkok dapat dilihat di Gambar 1.

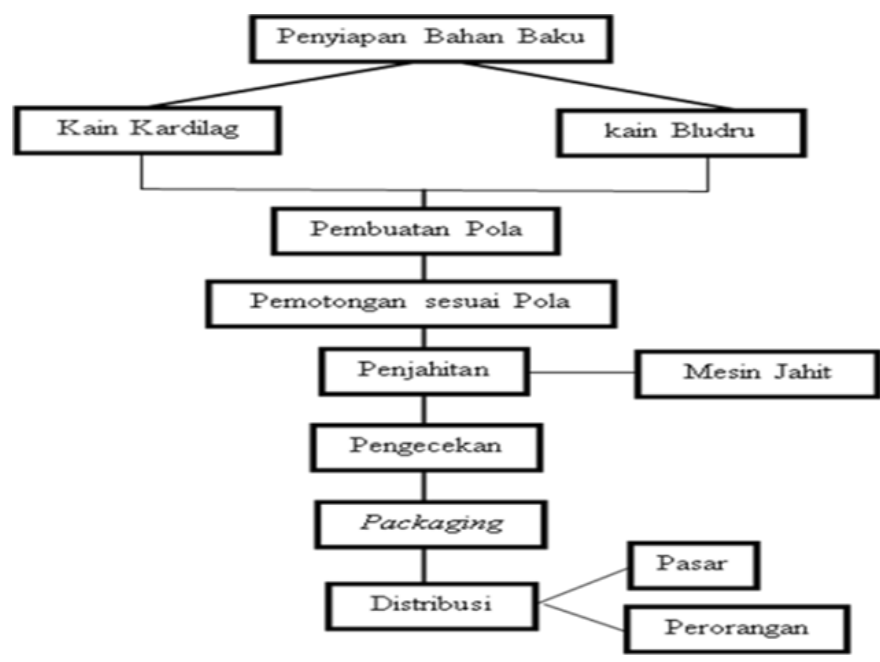

Gambar 1. Diagram alur pembuatan songkok UKM GSA Sumber: Data penelitian, 2021 
Berdasarkan Gambar 2 dapat diketahui mengenai diagram alur pembuatan songkok di UKM GSA. Diagram ini digunakan sebagai standar berlangsungnya proses produksi pada usaha tersebut. Tahapan pembuatan songkok dimulai dengan mempersiapkan bahan baku yaitu kain beludru dan kain akrdilag. Selanjutnya dilakukan penggambaran pola dan dilanjutkan dengan pengguntingan kain sesuai pola yang telah digambarkan di kain tersebut. Hasil potong sesuai pola selanjutnya dijahit dan dilakukan inspeksi. Selanjutnya setelah lolos inspeksi, dilakukan pengemasan dan didistribusikan pada toko-toko yang ada disekitar wilayah kota Gresik dan kota penyangga. Pada periode 3 bulan dapat diketahui bahwa jumlah defect berdasarkan hasil inspeksi di Tabel 4.

Tabel 4. Data defect

\begin{tabular}{ccccccc}
\hline \multirow{3}{*}{ Bulan } & \multicolumn{3}{c}{ Jenis defect (unit) } & Total \\
\cline { 2 - 4 } & $\begin{array}{c}\text { Pengesuman } \\
\text { Tidak Bagus }\end{array}$ & $\begin{array}{c}\text { Penjahitan } \\
\text { Tidak Rapi }\end{array}$ & $\begin{array}{c}\text { Pemotongan } \\
\text { Tidak Presisi }\end{array}$ & Output & \% defect \\
\hline April & 90 & 92 & 46 & 228 & 7042 & 3,23 \\
Mei & 139 & 90 & 60 & 289 & 8980 & 3,23 \\
Juni & 117 & 76 & 37 & 229 & 8694 & 2,63 \\
\hline \multicolumn{7}{c}{ Sumber: Data penelitian, 2021 }
\end{tabular}

Berdasarkan Tabel 4 dapat diketahui mengenai data dari defect produk songkok di UKM GSA. Data ini didapatkan penulis berdasarkan data historis dan wawancara dengan owner dari usaha tersebut. Adapun pada bulan April didapatkan defect produk sebesar 3,23\%, sedangkan pada bulan Mei didapatkan defect produk sebesar 3,23\% dan pada bulan Juni didapatkan defect produk sebesar 2,63\%.

Proses produksi songkok di UKM GSA masih ditemukan defect product. Adapun 3 jenis defectnya yaitu pengesuman tidak bagus, penjahitan tidak rapi dan pemotongan kain tidak presisi. Adapun $\%$ defect dalam produksi periode April hingga Juni tahun 2020 ditemukan 3,03\% dan hal itu di atas batas yang ditetapkan oleh si pemilik. Perhitungan ini menggunakan metode FMEA yaitu mengetahui nilai failure mode dari hasil kuesioner yang disebarkan di usaha UKM GSA. Adapun hasil perhitungan nilai severity (S), occurrence (O) dan detection (D) dari ketiga jenis defect tersebut ditabulasikan di Tabel 5.

Tabel 5. Hasil kuisioner SOD

\begin{tabular}{cccccc}
\hline \multirow{2}{*}{ Failure Mode } & & \multicolumn{3}{c}{ Responden } & Nilai \\
\cline { 3 - 5 } & & 1 & 2 & 3 & Tertinggi \\
\hline \multirow{2}{*}{ Pengesuman } & $\mathrm{S}$ & 8 & 8 & 8 & 8 \\
tidak bagus & $\mathrm{O}$ & 3 & 3 & 3 & 3 \\
& $\mathrm{D}$ & 5 & 6 & 6 & 6 \\
Penjahitan & $\mathrm{S}$ & 7 & 6 & 7 & 7 \\
tidak rapi & $\mathrm{O}$ & 3 & 2 & 3 & 3 \\
Pemotongan & $\mathrm{D}$ & 6 & 5 & 6 & 6 \\
tidak presisi & $\mathrm{S}$ & 6 & 7 & 6 & 7 \\
& $\mathrm{O}$ & 2 & 2 & 3 & 3 \\
\hline
\end{tabular}

Sumber: Data penelitian, 2021

Dari Tabel 5 diketahui jenis defect yang terjadi ditemukan 3 jenis failure mode yaitu pengesuman tidak bagus, penjahitan tidak rapi dan pemotongan tidak presisi. Dari hasil ini dilakukan perhitungan dan didapatkan severity, occurance, dan detection. Dari hasil tersebut selanjutnya digunakan sebagai dasar untuk menganalisis lebih lanjut mengenai penyebab dan pengendalian terhadap jenis defect. Tahapan ini dilakukan untuk menganalisa tingkat keparahan, probabilitas terjadinya kegagalan dan tingkat kontrol pendeteksian dari kegagalan yangterjadi pada proses produksi songkok. Breakdown penentuan RPN pada jenis defect proses pengesuman dapat dilihat di Tabel 6.

Tabel 6. Analisis FMEA pada proses pengesuman

\begin{tabular}{|c|c|c|c|c|c|c|c|}
\hline $\begin{array}{l}\text { Failure } \\
\text { Mode }\end{array}$ & $\begin{array}{c}\text { Failure } \\
\text { Effect }\end{array}$ & $S$ & Failure Cause & $\mathrm{O}$ & Control & $\mathrm{D}$ & RPN \\
\hline $\begin{array}{l}\text { Pengesuman } \\
\text { tidak bagus }\end{array}$ & $\begin{array}{c}\text { Produk } \\
\text { tidak sesuai } \\
\text { dengan } \\
\text { pengesuman }\end{array}$ & 8 & $\begin{array}{c}\text { kurang } \\
\text { berpengalaman } \\
\text { Kurang konsentrasi } \\
\text { Jarum tumpul }\end{array}$ & 3 & $\begin{array}{c}\text { Melakukan pelatihan } \\
\text { kerja } \\
\text { Melakukan pengawasan } \\
\text { operator } \\
\text { Mengganti jarum }\end{array}$ & 6 & 144 \\
\hline
\end{tabular}




\begin{tabular}{cc}
\hline Pengap & Memberikan ruangan \\
Kurangnya & yang banyak ventilasi \\
pencahayaan & Melakukan pergantian \\
lampu lebih terang \\
Melakukan pergantian \\
Bising & ruangan kedap suara \\
& Melakukan \\
Kualitas bahan & pengecekan Bahan \\
\hline
\end{tabular}

Sumber: Data penelitian, 2021

Berdasarkan Tabel 6 dapat diketahui mengenai hasil penilaian dan analisis menggunakan metode FMEA terhadap jenis defect proses pengesuman tidak bagus. Adapun hasilnya yaitu didapatkan nilai severity sebesar 8, occurance sebesar 3 dan detection sebesar 6. Nilai RPN pada proses penjahitan ditabulasikan di Tabel 7.

Tabel 7. Analisis FMEA pada proses penjahitan

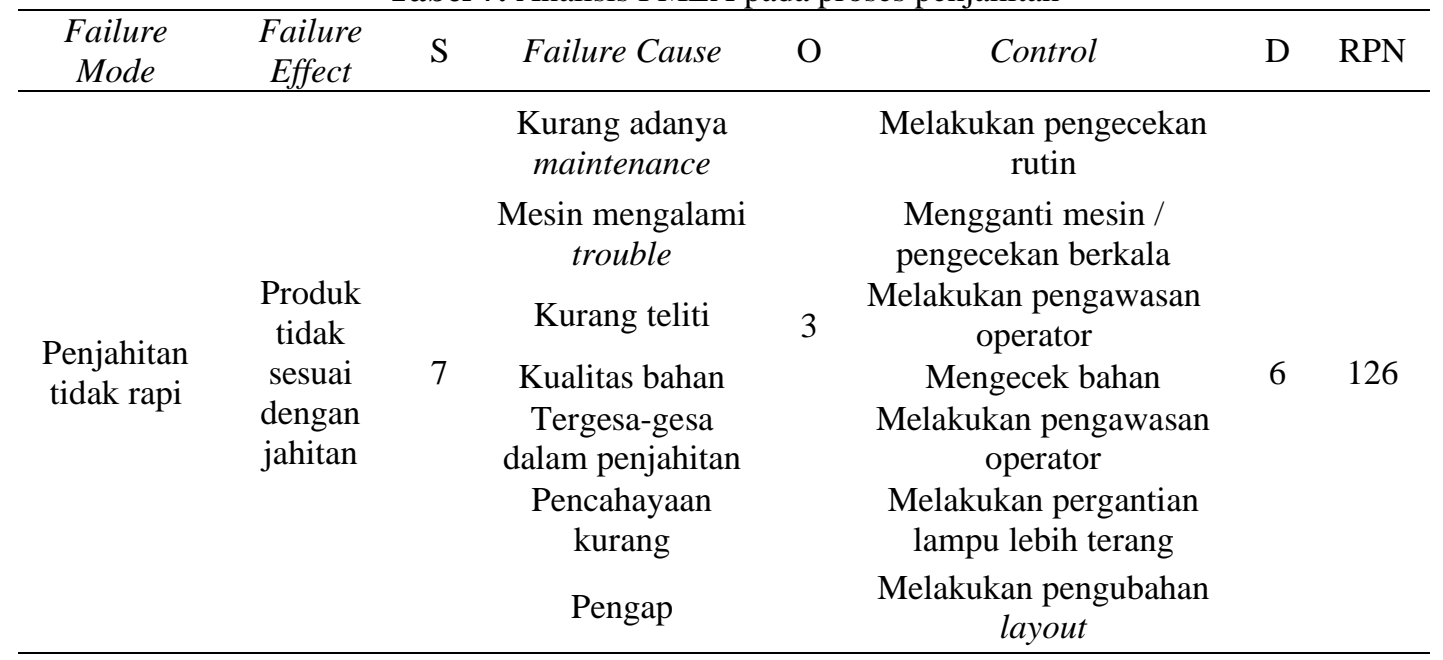

Sumber: Data penelitian, 2021

Berdasarkan Tabel 7 dapat diketahui mengenai hasil penilaian dan analisis menggunakan metode FMEA terhadap jenis defect proses penjahitan tidak rapi. Adapun hasilnya yaitu didapatkan nilai severity sebesar 7, occurance sebesar 3 dan detection sebesar 6. Jenis defect ketiga yaitu pemotongan tidak presisi dianalisis dan diketahui nilai RPN di Tabel 8.

Tabel 8. Analisis FMEA pada proses pemotongan

\begin{tabular}{|c|c|c|c|c|c|c|c|}
\hline $\begin{array}{l}\text { Failure } \\
\text { Mode }\end{array}$ & $\begin{array}{c}\text { Failure } \\
\text { Effect }\end{array}$ & $\mathrm{S}$ & Failure Cause & $\mathrm{O}$ & Control & $\mathrm{D}$ & RPN \\
\hline \multirow{4}{*}{$\begin{array}{l}\text { Pemotongan } \\
\text { tidak presisi }\end{array}$} & \multirow{4}{*}{$\begin{array}{c}\text { Produk } \\
\text { tidak } \\
\text { sesuai } \\
\text { dengan } \\
\text { ukuran }\end{array}$} & \multirow{4}{*}{7} & $\begin{array}{l}\text { Pisau potong } \\
\text { tumpul }\end{array}$ & & Melakukan pengecekan & \multirow{4}{*}{4} & \multirow{4}{*}{84} \\
\hline & & & Perawatan kurang & 3 & $\begin{array}{l}\text { Melakukan pengecekan } \\
\text { secara teratur }\end{array}$ & & \\
\hline & & & Kurang teliti & & Pengawasan operator & & \\
\hline & & & $\begin{array}{c}\text { Kurang } \\
\text { konsentrasi }\end{array}$ & & Pengawasan operator & & \\
\hline
\end{tabular}

Berdasarkan Tabel 8 dapat diketahui mengenai hasil penilaian dan analisis menggunakan metode FMEA terhadap jenis keccatan proses pemotongan tidak presisi. Adapun hasilnya yaitu didapatkan nilai severity sebesar 7, occurance sebesar 3, dan detection sebesar 4. Adapun untuk penyebab dan kontrol yang terjadi terlampir pada Tabel 8.

Penyebab dari kegagalan yang terjadi pada tabel analisis metode FMEA pada ketiga jenis defect mempunyai nilai RPN (Risk Priority Number) yang berbeda. Penentuan nilai RPN didapatkan dari hasil perkalian nilai severity, occurance dan detection. Peringkat nilai RPN pada ketiga jenis defect dapat dilihat di Tabel 9. 
Tabel 9. Nilai RPN

\begin{tabular}{ccccccc}
\hline No. & Failure Mode & S & O & D & RPN & Prioritas \\
\hline 1. & Pengesuman tidak bagus & 8 & 3 & 6 & 144 & 1 \\
2. & Penjahitan tidak rapi & 7 & 3 & 6 & 126 & 2 \\
3. & Pemotongan tidak presisi & 7 & 3 & 4 & 84 & 3 \\
\hline
\end{tabular}

Sumber: Data penelitian, 2021

Berdasarkan Tabel 9 dapat diketahui penilaian untuk ketiga jenis defect yang terjadi. Adapun jenis defect yang memiliki nilai RPN tertinggi haruslah dilakukan pengendalian terlebih dahulu guna menanggulangi dampak yang terjadi sehingga usaha tersebut pun tidak terganggu secara operasional dan finansialnya. Adapun urutan jenis defect yang harus dilakukan pengendalian berdasarkan skor nilai RPN yaitu pengesuman tidak bagus kemudian penjahitan tidak rapi dan pemotongan tidak presisi.

Dari penyebab kegagalan yang telah di analisis sebelumnya maka ditemukan bahwa yang paling mendominasi didasarkan pada hasil nilai RPN yang paling tinggi. Tahap selanjutnya yaitu melakukan breakdown dengan menggunakan metode Fault tree analysis (FTA). Penggambaran FTA merupakan penelusuran penyebab jenis defect dan mampu mengetahui penyebab yang paling dasar dari terjadinya sutau mode kegagalan di proses produksi songkok. Diagram FTA pada ketiga jenis defect dimulai dari Gambar 2 pada defect pengesuman tidak bagus.

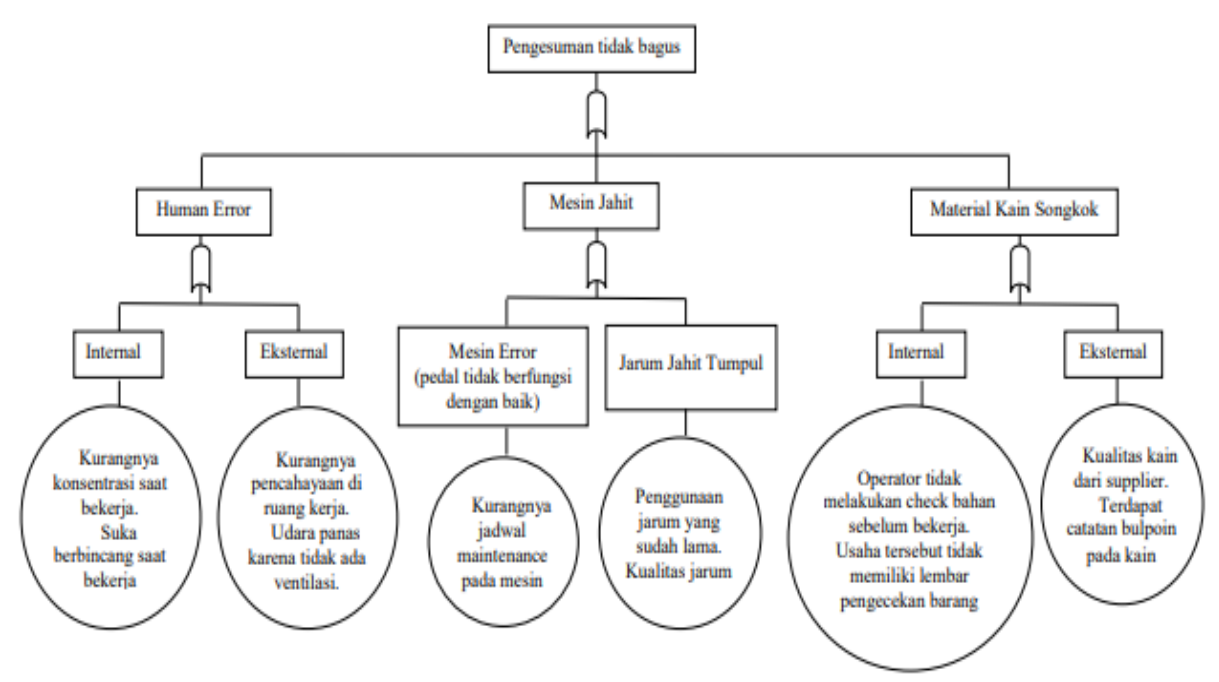

Gambar 2. Pohon kesalahan jenis Defect pengesuman tidak bagus Sumber : Data penelitian, 2021

Penelusuran penyebab defect sesuai Gambar 2 yaitu pengesuman tidak bagus diketahui disebabkan oleh tenaga kerja, peralatan produksi dan bahan baku. Pekerja tidak fokus dan kondisi fisik lingkungan kerja merupakan permasalahan internal dan eksternal yang menyebabkan terjadinya human error. Tidak adanya preventive maintenance menyebabkan mesin jahit tidak berfungsi dengan baik dan jarum jahit tumpul juga tidak dilakukan penggantian secara berkala. Tidak adanya lembar cheksheet inspeksi dan ketidakkonsistenan suplier menyebabkan merupakan faktor internal dan eksternal dari ketidaksesuaian kualitas bahan baku. Gambar 3 merupakan FTA kriteria defect penjahitan tidak rapi. 


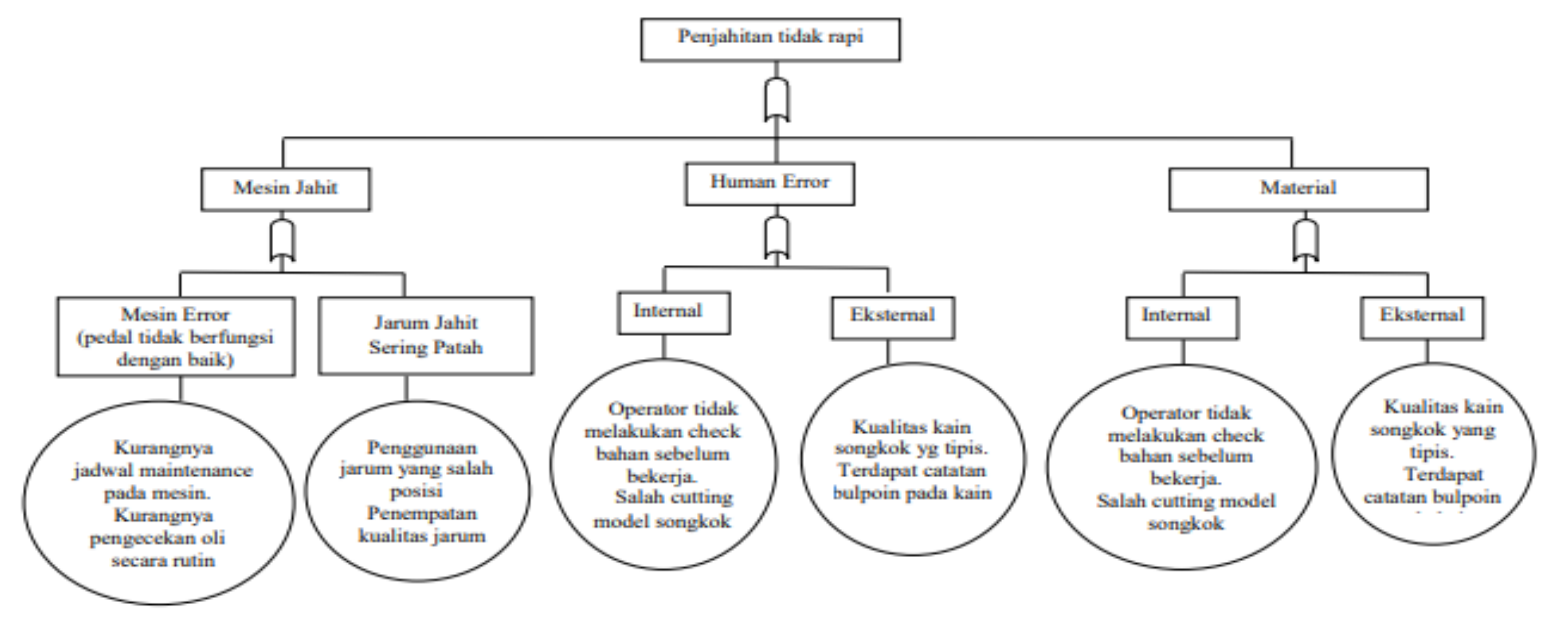

Gambar 3. Pohon kesalahan jenis defect penjahitan tidak rapi Sumber: Data penelitian, 2021

Pada Gambar 3 diketahui bahwa terdapat tiga faktor penyebab defect penjahitan tidak rapi, yaitu tenaga kerja, bahan baku, dan mesin jahit sebagai peralatan kerja. Mesin jahit tidak berfungsi disebabkan oleh tidak ada rutinitas cek oli dan penggunaan jarum yang keliru dan penempatan kualitas jarum menyebabkan jarum patah ketika digunakan dalam proses penjahitan. Kesalahan pemotongan kain tidak sesuai pola dan kualitas kain beludru dan kain kardigan tipis merupakan faktor internal dan eksternal yang menyebabkan human error. Tidak ada inspeksi bahan baku sebelum masuk pada tahap pemotongan dan kualitas bahan baku tidak sesuai standar merupakan faktor internal dan eksternal merupakan bagian dari bahan baku. Gambar 5 merupakan penggambaran FTA faktor defect hasil pemotongan tidak presisi.

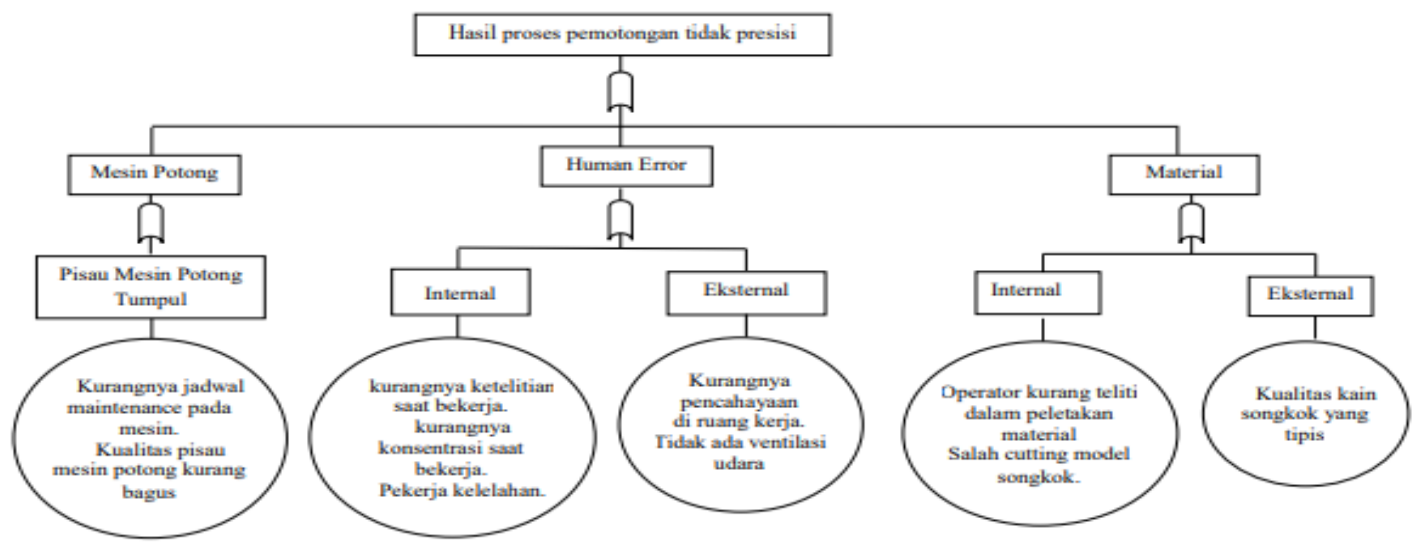

Gambar 4. Pohon kesalahan jenis defect pemotongan tidak presisi Sumber: Data penelitian, 2021

Berdasarkan Gambar 4 diketahui penyebab kegagalan yang paling mendominasi dari jenis defect pada proses pemotongan tidak sesuai pola. Mesin potong, human error dan bahan baku diketahui merupakan faktor yang mendominasi kesalahan pada jenis defect tersebut. Pisau mesin potong tumpul disebabkan oleh kualitas mesin pisau kurang bagus merupakan penyebab kegagalan mesin potong tersebut. Faktor internal dan eksternal dari kesalahan karyawan bagian pola dan pemotongan merupakan penyebab internal dan eksternal dari kondisi kesalahan pekerja. Kesalahan cutting pada model songkok dan kualitas kain songkok tipis merupakan penyebab ketidaksesuaian bahan baku yang mengakibatkan defect proses pemotongan tidak presisi.

Berdasarkan analisis FTA dan penelusuran mendasar dari tiga jenis defect di Gambar 2, Gambar 3, dan Gambar 4, maka langkah selanjutnya adalah memetakan skenario perbaikan guna mengeliminasi jenis defect. Pada tahap ini diberikan beberapa usulan untuk jenis kegagalan yang memiliki nilai RPN tertinggi sebagai prioritas penanggulangan kegagalan agar dapat diminimalisisir. Tabel 10 merupakan tabulasi skenario pengendalian defect. 
Tabel 10. Pengendalian jenis Defect

\begin{tabular}{ccc}
\hline $\begin{array}{c}\text { Jenis } \text { defect } \text { pada } \\
\text { produksi }\end{array}$ & Failure Cause & Pengendalian \\
\hline & kurang berpengalaman & Melakukan pelatihan kerja \\
Kurang konsentrasi & Jarum tumpul & Melakukan pengawasan operator \\
Pengesuman tidak & Mengganti jarum \\
bagus & Pengap & Memberikan ruangan ventilasi \\
& Kurangnya pencahayan & Melakukan pergantian lampu lebih terang \\
& diruangan produksi & Mising \\
Kualitas bahan & Sumber: Data penelitian, 2021
\end{tabular}

Berdasarkan Tabel 10 dapat diketahui mengenai rekomendasi untuk pengendalian dari jenis defect yang terjadi di UKM GSA dimana yang memiliki nilai RPN tertinggi. Jenis defect ini dilakukan usaha pengendalian terlebih dahulu guna untuk meminimalisir dampak yang terjadi. Pengendalian ini didasarkan atas rekomendasi dari penulis dan brainstorming dengan pemilik usaha.

\section{Kesimpulan}

Penelitian ini menghasilkan temuan sebagai berikut. Kesimpulan pertama yaitu teridentifikasi 3 jenis defect sepanjang alur produk songkok UKM GSA yaitu pengesuman tidak bagus, penjahitan tidak rapi dan pemotongan tidak presisi. Nilai persentase defect dalam produksi periode April hingga Juni tahun 2020 ditemukan 3,03\%. Simpulan kedua yaitu ditemukan bahwa jenis defect pengesuman tidak bagus memiliki prioritas pertama yang harus segera dilakukan perbaikan berdasarkan nilai RPN tertinggi yaitu sebesar 144 . Usulan perbaikan diberikan kepada jenis defect yang memiliki prioritas pertama untuk segera dilakukan perbaikan yaitu pada jenis defect pengesuman tidak bagus. Temuan ketiga yaitu berdasarkan hasil penelusuran mendasar FTA penyebab ketiga jenis defect tersebut, diketahui bahwa tenaga kerja, peralatan kerja, dan bahan baku merupakan faktor input yang menyebabkan terjadinya defect.

Usulan skenario perbaikan yang direkomendasikan terdapat tiga hal dijabarkan sebagai berikut. Penambahan fasilitas infrastruktur untuk menunjang kenyamanan bagi tenaga kerja di tempat kerja. Pon kedua yaitu melakukan pengawasan rutin tenaga kerja di tempat kerja agar selalu fokus terhadap pekerjaan yang sedang dikerjakan. Bagi owner diharapkan untuk segera melakukan prioritas perbaikan agar usaha yang dijalankan dapat terus meningkat kualitas produk.

Kelemahan penelitian ini yaitu tidak membahas secara rinci faktor metode kerja, postur kerja karyawan, urutan pekerjaan, dan beban kerja. Penelitian selanjutnya diharapkan dilakukan dengan mempertimbangkan ketiga faktor tersebut sehingga hasil penelusuran risiko penyebab defect dapat dianalisis secara lebih komprehensif.

\section{Referensi}

[1] Masrofah dan H. Firdaus, "Analisis defect produk baju muslim di Pd. Yarico Collection menggunakan metode Failure Mode and effect analysis," JMTSI (J. Media Teknik dan Sistem Industri), Vol. 2 (2), hal. 43-55, 2018.

[2] D. P. Pradana, S. Rahayuningsih, dan H. B. Santoso, "Analisis reject produk dalam proses return di PT. Gunawan Fajar menggunakan metode FMEA," JURMATIS (J. Mahasiswa Teknik Industri Universitas Kediri), Vol. 2 (1), hal. 44-53, 2020.

[3] P. S. Diana, F. M. Klara, T. Calvin, Mellysa, dan U. H. Naniek, "Analisis penyebab defect menggunakan metode FMEA dan FTA pada departemen final sanding PT Ebako Nusantara," Prosiding SNSTKe-9, Semarang, 2018, hal. 125-130.

[4] Y. A. Fauzi dan H. Aulawi, "Analisis pengendalian kualitas produk peci jenis overset yang defect di Pd. Panduan Illahi dengan menggunakan metode Fault Tree Analysis (FTA) dan metode Failure Mode and Effect Analysis (FMEA)," J. STT, Vol. 14 (1), hal. 29-34, 2016.

[5] M. Hidayat dan R. Rochmoeljati, "Perbaikan kualitas produk menggunakan metode Fault Tree Analysis (FTA) dan Failure Mode and Effect Analysis (FMEA) Di PT. Ifmfi Surabaya," JUMINTEN, Vol. 1 (4), hal. 70-80, 2020.

[6] S. M. Ahmad dan A. A. Yusanto, "Analisis penurunan defect pada proses manufaktur komponen kendaraan bermotor dengan Metode Failure Mode and Effect Analysis (FMEA)," J. Kajian Teknik Industri, Vol. 5 (2), hal. 66-77, 2020 
[7] S. Joko, "Analisis penyebab defect produk sepatu Terrex Ax2 Goretex dengan menggunakan Metode Fault Tree Analysis (FTA) dan Failure Mode and Effect Analysis (FMEA) di PT. Panarub Industri," JIM (Journal of Industrial Manufacturing), Vol. 3 (1), hal. 15-22, 2018.

[8] N. Ardiansyah dan C. H. Wahyuni, "Analisis kualitas produk dengan menggunakan Metode FMEA dan FTA di Exotic UKM Intako," J. PROZIMA (Productivity, Optimization, and manufacturing system), Vol. 2 (2), hal. 58-63, 2018.

[9] H. Muhammar dan H. H. Azwir, "Usulan perbaikan proses pencampuran powder jelly dengan Metode Failure Mode and Effect Analysis (FMEA) dan pengurangan waktu proses di pabrik pangan," J. Industrial Engineering, Vol. 4 (1), hal. 9-20, 2019.

[10] R. Saputra dan D. T. Santoso, "Analisis kegagalan proses produksi plastik pada mesin cutting di PT PKF dengan pendekatan Failure Mode and Effect Analysis dan diagram pareto," J. Barometer UINSKA, Vol. 6 (1), hal. 322-327, 2021.

[11] D. Dananjaya, D. Hetharia, dan S. Adisuwiryo, "Perbaikan kualitas produk nestable 100 di PT. Cahaya Metal Perkasa," J. Teknik Industri, Vol. 10 (3), hal. 266-274, $2020 .$.

[12] Supriyadi dan M. Nabilla, "Analisa kegagalan produk CLIP RI dengan pendekatan Failure Mode and Effect Analysis (FMEA)," J. of Industrial Engineering, Vol. 5 (2), hal. 101-109, 2020.

[13] K. N. Dewi dan L. M. Singgih, "Perbaikan kualitas proses thermoforming round drinking cups menggunakan FMEA,” J. Teknik ITS, Vol. 8 (1), hal. 30-34, 2019.

[14] Mashufaf dan M. Munir, "Upaya menurunkan tingkat defect produk PSST Slice Mushrooms $4 \mathrm{Oz}$ dengan metode FMEA (Failure Mode and Effect Analysis) di PT. ETR Purwodadi," J. Knowledge Industrial Engineering (JKIE), Vol. 6 (2), hal. 66-74, 2019.

[15] Gaspersz, Total quality management untuk praktisi bisnis dan industry, Vinchristo Publication, Jakarta, 2011. 